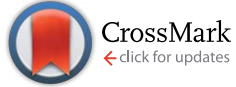

Cite this: Nanoscale, 2014, 6, 11963

\title{
Synthesis and exceptional thermal stability of Mg-based bimetallic nanoparticles during hydrogenation $\uparrow$
}

\author{
Gopi Krishnan, ${ }^{\text {*a }}$ Raluca F. Negrea, ${ }^{\mathrm{b}}$ Corneliu Ghica, ${ }^{\mathrm{b}}$ Gert H. ten Brink, ${ }^{a}$ Bart J. Kooi \\ and George Palasantzas ${ }^{a}$
}

\begin{abstract}
Here we report the extraordinary thermal stability of Mg rich bimetallic nanoparticles (NPs), which is important for hydrogen storage technology. The enhanced NP stability is accomplished because of two critical improvements: (i) no void development within NPs (nanoscale Kirkendall effect) during their formation and (ii) suppressed Mg evaporation and NP hollowing during Mg hydrogenation at elevated temperature. The mechanism leading to the improved thermal stability of $\mathrm{Mg}$-based bimetallic NPs is shown to be due to $\mathrm{MgH}_{2}$ hydride formation before evaporation can take place. These findings were tested for various compositions of $\mathrm{Mg}$ with $\mathrm{Ni}, \mathrm{Cu}$, and $\mathrm{Ti}$, which are interesting combinations of materials for hydrogen storage systems. To achieve this we first demonstrate the synthesis mechanism of $\mathrm{Mg}-\mathrm{Ni}$ and $\mathrm{Mg}-\mathrm{Cu} \mathrm{NPs}$, which is well controlled at the single particle level, in order to accomplish multi-shell, alloy and intermetallic structures of interest for hydrogen storage tests. Aberration corrected transmission electron microscopy was carried out to unravel the detailed atomic structure and composition of the bimetallic NPs after production, processing, and hydrogenation. Finally, a simple and effective methodology is proposed for tuning the composition of the Mg-based bimetallic NPs based on the temperature-dependent nucleation behavior of NPs in the gas-phase.
\end{abstract}

Received 10th July 2014

Accepted 7th August 2014

DOI: $10.1039 / c 4 n r 03885 a$

www.rsc.org/nanoscale formation occurs for NPs larger than $10 \mathrm{~nm}$, and that hollow MgO NPs are formed for NPs less than $10 \mathrm{~nm}$ due to the oxidation induced nanoscale Kirkendall effect during NP production. ${ }^{3}$ The latter is the result of faster outward diffusion of $\mathrm{Mg}$ ions with simultaneous inward diffusion of vacancies to compensate for the unequal material flow due to the different atomic diffusivities. Furthermore, the vacancies supersaturate to form voids within the NPs. As a result smaller Mg NPs $(<10 \mathrm{~nm})$ completely transform into hollow NPs, and the larger NPs (>10 nm) develop voids in the vicinity of their facets within the nanoparticles and these voids grow further during hydrogenation. ${ }^{3}$ Although these phenomena present formidable barriers for the successful implementation of Mg NPs in hydrogen storage, the use of Mg bimetallic NPs might alleviate the issues above.

Indeed, bimetallic NPs are considered as an interesting class of materials, where the chemical and physical properties can be tailored based on composition, size, and atomic ordering. In fact, Mg-based bimetallic NPs produced to date are mostly based on bottom up methods consisting of inert-gas condensation, ${ }^{6}$ spark discharge generation, ${ }^{7}$ and the hydrogen plasmametal reaction/arc method. ${ }^{8,9}$ However, none of these methods have shown a well-controlled tuning of sizes, structural motifs, and composition of bimetallic NPs. In addition, although the gas-phase synthesis of NPs via DC-magnetron sputtering is well known to produce metallic and bimetallic NPs, only recently the
${ }^{a}$ Zernike Institute for Advanced Materials and the Materials Innovation Institute, University of Groningen, Nijenborgh 4, 9747 AG Groningen, The Netherlands. E-mail: gopi.k.krish@gmail.com

${ }^{b}$ National Institute for Materials Physics, P.O. Box MG-7, Magurele, Ilfov, RO 77125, Romania

$\dagger$ Electronic supplementary information (ESI): Experimental details including target arrangement, schematic of the gas phase synthesis set up, and TEM images of Mg-Ni, Mg-Cu and Mg-Ti NPs. See DOI: 10.1039/c4nr03885a 
capability of this technique to control different bimetallic structures was demonstrated. ${ }^{\mathbf{1 0 1 1}}$ In fact, we demonstrated a general methodology to tune various structures of, bulk immiscible, bimetallic NPs at the single particle level using our home modified Mantis nanocluster source. ${ }^{10}$

Bimetallic Mg-rich based NPs combined with other metals like $\mathrm{Ni}, \mathrm{Cu}$ and $\mathrm{Ti}$, which are interesting as hydrogen storage materials, ${ }^{1}$ are highly challenging to synthesize using gas-phase synthesis with a controlled composition and structure. This can be attributed to the different physical properties (e.g. vapor pressure and melting point) of $\mathrm{Mg}$ and the combined elements (e.g. $\mathrm{Ni}, \mathrm{Cu}$ and $\mathrm{Ti}$ ), which affect the size, nucleation, and the composition of the bimetallic NPs. These factors demand change of sputtering target composition in order to alter the NP chemical composition. Here, however, we will demonstrate that it is feasible to achieve composition tuning of $\mathrm{Mg}-\mathrm{Ni}, \mathrm{Mg}-\mathrm{Cu}$, and $\mathrm{Mg}$-Ti NPs based on a temperature dependent nucleation behavior of $\mathrm{Mg}, \mathrm{Ni}$, and $\mathrm{Cu}$ using only a single composition (sectioned) material target for magnetron sputtering and gas phase synthesis of NPs. To the best of our knowledge, tuning different structures of Mg-based bimetallic NPs, tailoring composition during production, and thermal stability have not been reported before.

Hence in this article we demonstrate: (i) the complete suppression of voids during the synthesis of $\mathrm{Mg}-\mathrm{Ni}, \mathrm{Mg}-\mathrm{Cu}$, and $\mathrm{Mg}$-Ti NPs with $\mathrm{Mg}$ rich composition, (ii) the improved thermal stability of $\mathrm{Mg}-(\mathrm{Ni}, \mathrm{Cu}, \mathrm{Ti})$ without the formation of a hollow Mg core during hydrogenation of NPs at $250{ }^{\circ} \mathrm{C}$ and 10 bar pressure of $\mathrm{H}_{2}$, and (iii) a synthesis methodology to tailor the composition and different structures of $\mathrm{Mg}$-based bimetallic NPs at a single particle level, where proof for the different structures comes from aberration corrected transmission electron microscopy. Finally this paper is dedicated only to the synthesis and in depth characterization of $\mathrm{Mg}$ based bimetallic nanoparticles, as well as their thermal stability during hydrogenation.

\section{Experimental methods}

\section{Synthesis}

The $\mathrm{Mg}-\mathrm{Ni}, \mathrm{Mg}-\mathrm{Cu}$ and $\mathrm{Mg}-\mathrm{Ti}$ bimetallic nanoparticles with various structures (alloys, multishell and multiphase) and compositions were produced by using a home modified nanoparticle system Nanosys500 from Mantis Deposition Ltd. (http:/www.mantisdeposition.com). The sample chamber was evacuated to a base pressure of $\sim 1 \times 10^{-8} \mathrm{mbar}$ with an oxygen partial pressure of $\sim 10^{-11}$ mbar. Supersaturated metal vapor is produced by magnetron sputtering of a sectioned target shown (99.95\% purity of $\mathrm{Mg}, \mathrm{Ni}, \mathrm{Cu}$ and $\mathrm{Ti}$ as obtained from Alpha Aesar) in Fig. 1(a) or (b) in an inert argon atmosphere (pressure of $\sim 0.25$ mbar with an appropriate discharge current depending on the choice of the structures that were synthesized). The supersaturated metal vapor is then cooled by argon gas in order to form nuclei, which can subsequently grow into nanoparticles. The nanoparticles formed in the aggregation volume are removed fast by the use of argon which act as a drift and sputter gas. The tuning of the thermal environment and energy was made by varying the discharge current and by keeping the pressure constant inside the aggregation volume.

\section{TEM analysis}

The nanoparticles transported from the aggregation volume were deposited onto $25 \mathrm{~nm}$ thick silicon-nitride membranes, which were used for Transmission Electron Microscopy (TEM) analysis using a JEOL 2010F and JEOL ARM 200F aberration corrected TEM. The TEM investigations performed on a JEM ARM 200F electron microscope is provided with a probe Cs corrector and a Quantum SE Gatan Image Filter. The microscope was operated at $200 \mathrm{kV}$ acceleration voltage. For the EELS spectral images we used a convergence semiangle of $20 \mathrm{mrad}$ and a collection semiangle of $49 \mathrm{mrad}$ for a camera length of $3 \mathrm{~cm}$. In order to create a composition line profile across the nanoparticles, an EEL spectrum has been extracted from each pixel along the diameter of the nanoparticle. Each extracted spectrum has been quantified using the Hartree-Slater model for the differential cross-section calculation and the power-law for the background model.

\section{Results and discussion}

Fig. 1(a) and (b) show bright-field TEM images of $\mathrm{Mg}-\mathrm{Ni}$ nanoparticles before and after hydrogenation. The NPs show no void formation during their production and no $\mathrm{Mg}$ evaporation after hydrogenation at $250{ }^{\circ} \mathrm{C}$ (under 10 bar $\mathrm{H}_{2}$ pressure for $72 \mathrm{~h}$ ). Therefore the present bimetallic NPs show a greatly improved thermal stability as compared to monometallic $\mathrm{Mg}$ NPs. ${ }^{3}$ The compositions of the Mg-rich NPs were $80 \pm 3$ at $\% \mathrm{Mg}$ and $20 \pm 3$ at\% Ni (measured using STEM-EELS analysis) with the as-prepared NP structure being solid solution. Our previous analysis has proven that Mg NPs can evaporate and form hollow $\mathrm{Mg}$ very rapidly at this temperature and $\mathrm{H}_{2}$ pressure. ${ }^{3}$ Moreover, also bimetallic $\mathrm{Mg}-\mathrm{Cu}$ and $\mathrm{Mg}-\mathrm{Ti}$ NPs with similar compositions were tested for improved stability, as shown in the brightfield TEM images of Fig. 1(d, e, g and h).

Although the $\mathrm{MgH}_{2}$ formation can be achieved at lower $\mathrm{H}_{2}$ pressure and time, our motivation for prolonged exposure is to observe their long term thermal stability in comparison with monometallic Mg NPs. The diffraction patterns of Fig. 1(c), (f) and (i) confirm that the corresponding NPs are fully hydrogenated having an $\alpha-\mathrm{MgH}_{2}$ rutile phase (see the HRTEM image in Fig. 3(b) in the ESI $\dagger$ ). After hydrogenation, $\mathrm{Mg}-\mathrm{Ni}$ and $\mathrm{Mg}-\mathrm{Cu}$ NPs show segregation and phase separation of $\mathrm{Ni}$ and $\mathrm{Cu}$ to the center of (most of) the NPs that are shown in Fig. 1 (compare (b) with (a) and (e) with (d)). This segregation phenomenon can be attributed to the following systematic reasons: (1) lower enthalpy of $\mathrm{MgH}_{2}$ formation $\left(-37 \mathrm{~kJ} \mathrm{~mol}^{-1} \mathrm{H}\right.$ ), as compared to $\mathrm{Ni}\left(4.5 \mathrm{~kJ} \mathrm{~mol}^{-1} \mathrm{H}\right)$ and $\mathrm{Cu}\left(24 \mathrm{~kJ} \mathrm{~mol}^{-1} \mathrm{H}\right)$, which acts as a driving force for segregation; (2) enhanced atomic mobility of atoms under the influence of absorbed hydrogen in the NPs, as observed in bulk materials; ${ }^{\mathbf{1 2 - 1 4}}$ (3) surface energy difference between $\mathrm{MgH}_{2}$ and $\mathrm{Ni}$ (or $\mathrm{Cu}$ ) drives $\mathrm{Mg}$ atoms to the surface to form an $\mathrm{MgH}_{2}$ shell, and simultaneously $\mathrm{Ni}$ (or $\mathrm{Cu}$ ) atoms are 


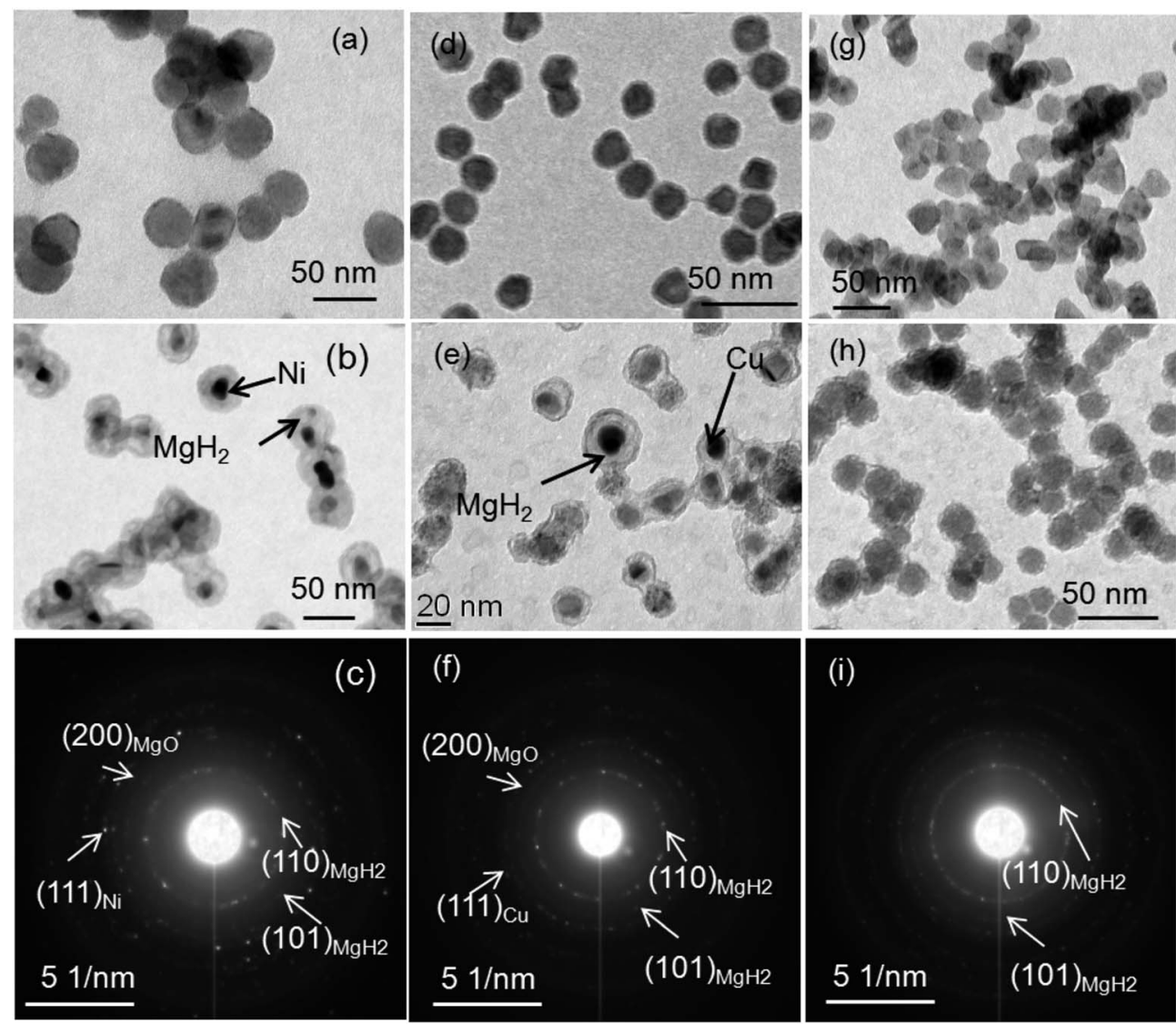

Fig. 1 TEM results of $\mathrm{Mg}-\mathrm{Ni}(\mathrm{a}-\mathrm{c}), \mathrm{Mg}-\mathrm{Cu}(\mathrm{d}-\mathrm{f})$ and $\mathrm{Mg}-\mathrm{Ti}(\mathrm{g}-\mathrm{i}) \mathrm{NPs}$ before and after hydrogenation without void formation. (a, $\mathrm{d}$ and $\mathrm{g}$ ) Brightfield TEM images of Mg-Ni NPs with $80 \pm 3$ at\% of Mg, Mg-Cu NPs with $81 \pm 3$ at\% of Mg and Mg-Ti NPs with $85 \pm 4$ at\% of Mg before hydrogenation. (b, e and h) Bright field TEM images of $\mathrm{Mg}-\mathrm{Ni}, \mathrm{Mg}-\mathrm{Cu}$ and $\mathrm{Mg}-\mathrm{Ti} \mathrm{NPs}$ after hydrogenation at $250{ }^{\circ} \mathrm{C}$ and 10 bar $\mathrm{H}_{2} . \mathrm{Mg}-\mathrm{Ni}$ and $\mathrm{Mg}-\mathrm{Cu} \mathrm{NPs}$ exhibit phase separation of $\mathrm{Ni}$ and $\mathrm{Cu}$ (center), and $\mathrm{MgH}_{2}$ on the outer shell. The $\mathrm{Mg}-\mathrm{Ti}$ NPs do not show any phase separation. (c, $\mathrm{f}$ and i) Diffraction patterns of the $\mathrm{Mg}-\mathrm{Ni}, \mathrm{Mg}-\mathrm{Cu}$ and $\mathrm{Mg}-\mathrm{Ti} \mathrm{NPs}$ after hydrogenation with a clear indication of the rutile $\mathrm{MgH}_{2}$ formation in all cases.

pushed to the center where they finally form a $\mathrm{Ni}($ or $\mathrm{Cu}$ ) core (see the HAADF-STEM image in Fig. 3(a) in the ESI $\dagger$ ).

Our initial observations indicate that phase separation does not take place when $\mathrm{Mg}-\mathrm{Ni}$ NPs are annealed at $250{ }^{\circ} \mathrm{C}$ in a vacuum, indicating the clear influence of hydrogen on phase separation. In contrast, phase separation upon hydrogenation (as observed for $\mathrm{Mg}-\mathrm{Ni}$ and $\mathrm{Mg}-\mathrm{Cu} \mathrm{NPs}$ ) does not occur for Mg-Ti NPs indicating their unique behavior as it is shown in Fig. 1(h). However, the lower enthalpy of $\mathrm{TiH}_{2}$ formation $(-72 \mathrm{~kJ}$ $\left.\mathrm{mol}^{-1} \mathrm{H}\right)$ as compared to $\mathrm{MgH}_{2}\left(-37 \mathrm{~kJ} \mathrm{~mol}^{-1} \mathrm{H}\right)$ indicates that hydrogen should in general still favor phase separation. Moreover, in the case of Mg-Ti thin films phase separation was not observed also after hydrogenation at low temperature and pressure. ${ }^{15,16}$ The coherent structure and equal molar volume of $\mathrm{TiH}_{2}, \mathrm{Mg}$ and influence of hydrogen on the stabilization of $\mathrm{Mg}-\mathrm{Ti}$ alloys by reducing the enthalpy of formation from positive to negative $(\mathrm{Mg}$ and $\mathrm{Ti}$ are immiscible systems with a positive enthalpy of formation) are two reasons considered to inhibit phase segregation in thin films..$^{15,16}$ Nevertheless, a full understanding is still missing. Our detailed study to improve the understanding of this behavior for Mg-Ti NPs will be reported elsewhere. In any case enhanced thermal stability of bimetallic Mg NPs is preserved for an Mg concentration of less than $<85 \mathrm{at} \%$, which is valid for $\mathrm{Ni}, \mathrm{Cu}$ and $\mathrm{Ti}$. Above this $\mathrm{Mg}$ concentration void formation and voiding of $\mathrm{Mg}$ cores slowly start to develop during synthesis and hydrogenation depending on the NP size where it is of course more pronounced for smaller NPs (see Fig. 4 in the ESI $\dagger$ ).

The suppression of void formation in Mg-based bimetallic NPs during their production can be explained qualitatively by three important factors: (1) the presence of $\mathrm{Ni}, \mathrm{Cu}$ and $\mathrm{Ti}$ at the interface of the metal/metal-oxide $(\mathrm{Mg} / \mathrm{MgO})$ suppresses vacancy supersaturation and thereby blocks the coalescence of vacancies to form voids or reduces initial nucleating sites for void formation and subsequent growth; (2) the presence of vacancy sinks in bimetallic Mg NPs near the metal/metaloxide interface for vacancy annihilation; (3) outward diffusion of $\mathrm{Mg}$ becomes slow during the process of hydrogenation by the formation of intermetallic/alloy near the interface. Indeed, a similar kind of strategy has been employed in thin films of two metals separated with an intermediate alloy layer (made of a combination of the same metals), which efficiently inhibits the void formation due to their reduced atomic diffusivity. ${ }^{17,18}$ 
More important is the fact that the Mg-based bimetallic NPs also show an increased thermal stability during hydrogenation as compared to pure $\mathrm{Mg}$ nanoparticles. This can be attributed to the solid solution (alloy) structure of Mg-based bimetallic NPs, which significantly lowers the $\mathrm{Mg}$ vapor pressure as compared to monometallic NPs. The latter can be understood by the fact that the added metals $(\mathrm{Ni}, \mathrm{Cu}$, and $\mathrm{Ti})$ have higher melting and boiling points than $\mathrm{Mg}$ (in general high boiling point metals have low vapor pressure). For example, $\mathrm{Ni}$ has (compared to $\mathrm{Mg}$ ) low vapor pressure and high thermal stability at all relevant temperatures. Therefore, Mg-based bimetallic NPs with an alloy structure should show better thermal stability than $\mathrm{Mg}$. This is confirmed here for $\mathrm{Mg}-\mathrm{Ni}, \mathrm{Mg}-\mathrm{Cu}$ and $\mathrm{Mg}-\mathrm{Ti}$ bimetallic NPs with $\mathrm{Mg}$-rich composition.

During hydrogenation the segregation and phase separation do not lead to void formation within NPs. This can be the effect of stable $\mathrm{MgH}_{2}$ formation during phase separation of $\mathrm{Ni}$, as $\mathrm{MgH}_{2}$ is thermally more stable than $\mathrm{Mg}$, which prevents hollowing of $\mathrm{Mg}$ and increases the thermal stability of NPs. In the case of monometallic Mg NPs we observed that the Mg evaporation takes place rapidly before the formation of the $\mathrm{MgH}_{2}$ phase occurs due to their high vapor pressure. Therefore, in the case of Mg-based bimetallic NPs the enhanced stability arises from: (a) the lower vapor pressure of $\mathrm{Mg}$ due to the alloy structure, which retards the $\mathrm{Mg}$ evaporation, and (b) subsequently allowed the formation of $\mathrm{MgH}_{2}$, which further clearly enhances the thermal stability of the Mg-based NPs.

To support this claim we demonstrate that Mg-Ni NPs, with an initial multi-shell structure as shown in Fig. 3(a), when they undergo hydrogenation under two different conditions $\left(250{ }^{\circ} \mathrm{C}\right.$ at 10 bar $\mathrm{H}_{2}$, and $150{ }^{\circ} \mathrm{C}$ at 5 bar $\mathrm{H}_{2}$ ) give two different outcomes. First, the Mg-Ni NPs at $250{ }^{\circ} \mathrm{C}$ and 10 bar $\mathrm{H}_{2}$ show phase separation, similar to that observed in Fig. 1(a), while in

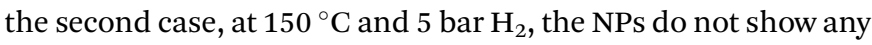
phase separation and $\mathrm{MgH}_{2}$ formation. Moreover, the latter NPs only show the presence of an $\mathrm{MgO}$ shell and complete absence of $\mathrm{Mg}$ in the core of the NP. Ni of course remains, which also suggests that when $\mathrm{Mg}$ is not hydrided sufficiently fast it can still easily evaporate (Fig. 5 in the ESI $\dagger$ ).

In order to be able to control this void formation (nanoscale Kirkendall effect) and thermal stability of $\mathrm{Mg}$ rich bimetallic NPs we have developed a synthesis methodology to tune the composition and structure of the Mg-based bimetallic NPs, where for $\mathrm{Mg}-\mathrm{Ni}$ and $\mathrm{Mg}-\mathrm{Cu}$ three categories can be distinguished: multi-shell/onion structures, intermetallic compounds, and (solid-solution) alloy structures. The nucleation and growth of the bimetallic NPs were controlled via regulation of the discharge current applied to the material target for DC magnetron sputtering, which is one of the possible paths to control the NP structures formed during high pressure gas-phase condensation. ${ }^{\mathbf{1 0 , 1 9}}$ Indeed, regulation of the discharge current gives a direct control over the thermal environment the NPs experience during their formation, since it allows tuning of the density of the plasma and thus the energy of the sputtering Ar ions and growing NPs. As a result, this process allows tuning of different temperature regimes (as the discharge current increases the plasma temperature also increases under constant gas flow conditions) and cooling rates for the NPS during their formation. ${ }^{10}$ The temperature/thermal environment affects strongly the NP nuclei formation, and their nucleation rate, which is strongly element specific at different discharge currents. Effectively we can thus use this dependence to tune the structure and composition of the bimetallic NPs.

In general during binary element thin film formation the elements with high vapor pressure (under the synthesis conditions) will share higher percentages of the composition in the final structure. However, in bimetallic NPs, e.g. $\mathrm{Mg}-\mathrm{Ni}$, the high vapor pressure element $(\mathrm{Mg})$ does not dominate the final composition of the NPs but rather it depends on the rate of nuclei formation of $\mathrm{Ni}$ (high melting point element) and subsequent growth (and intermixing) of both $\mathrm{Mg}$ and $\mathrm{Ni}$. This is especially valid when the combined elements have large differences in their physical properties (e.g. vapor pressure and melting points). From our previous observations, a metal with higher melting point (higher solidification temperature) will always tend to be enriched in the NPs compared to the accompanying metal in the binary system. ${ }^{10}$ Fig. 2(a) shows a schematic of the bimetallic NP formation at different discharge currents at a constant flow rate, while Fig. 2(b) shows a schematic of the temperature profile the NPs experience at different discharge currents.

Furthermore, Fig. 3(a) shows a bright-field TEM image of $\mathrm{Mg}-\mathrm{Ni}$ nanoparticles synthesized at $0.250 \mathrm{~A}$ discharge current showing a multi-shell structure (i.e. as opposed to the alloy structure shown in Fig. 1(a)), which can be confirmed from the observed variations in contrast. Fig. 3(c) shows a STEM-EELS

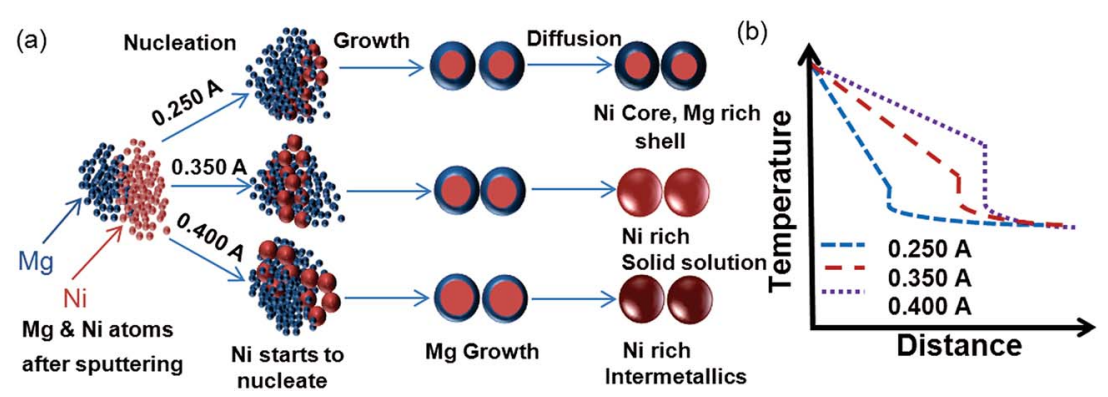

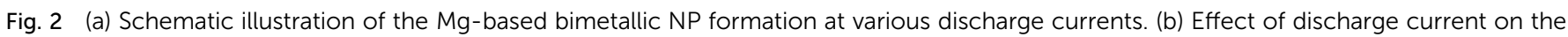
temperature profile and cooling rate of the NPs. 


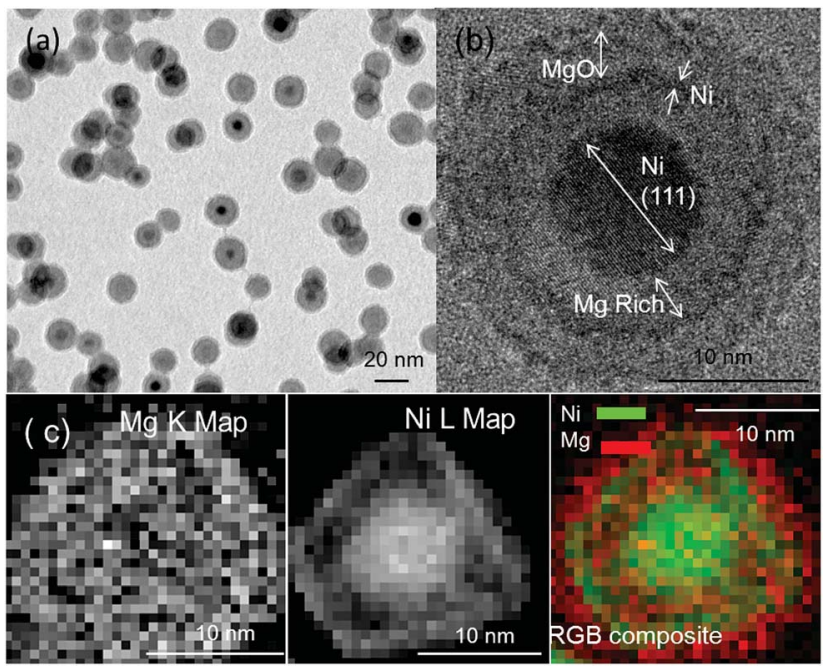

Fig. 3 Bright-field TEM images of the Mg-Ni NPs produced at $0.250 \mathrm{~A}$ discharge current. (b) HRTEM image of the Mg-Ni NP showing a Ni core in which the (111) planes are resolved. (c) STEM-EELS mapping of the $\mathrm{Mg}-\mathrm{Ni} \mathrm{NP}$.

spectral mapping of a corresponding NP, which reveals the multi-shell structure. The NP shows a Ni-core with towards the outside a sequence of $\mathrm{Mg}$ rich/ $\mathrm{Ni} / \mathrm{MgO}$ shells as indicated in the figure, where particularly the intermediate $\mathrm{Ni}$ shell is relatively thin. Fig. 3(b) shows a HRTEM image of the NPs indicating the $\mathrm{Ni}$ (111) lattice planes, which confirms the presence of $\mathrm{Ni}$ as a core. To understand more in detail the composition of $\mathrm{Mg}$ and $\mathrm{Ni}$, we present in Fig. 4(a) and (b) a line profile of the NP composition from the STEM-EELS spectrum. The composition distribution in a single NP can be clearly seen along with the Ni and $\mathrm{Mg}$ rich regions confirming the presence of the multi-shell structure.

In order to understand this multi-shell structure formation, we schematically illustrate this process for $\mathrm{Mg}-\mathrm{Ni} \mathrm{NPs}$ in Fig. 4(c), and show how oxidation plays a central role. Unlike most other metals, $\mathrm{Mg}$ NPs form an oxide shell during their production, even in ultra-high vacuum systems, due to the very high affinity of $\mathrm{Mg}$ for oxygen. ${ }^{5}$ As shown in Fig. 4(c), the particle produced initially will have a core-shell structure with $\mathrm{Ni}$ as a core, and an Mg-rich region as a shell. During oxidation $\mathrm{Mg}$ atoms diffuse into the surface while the $\mathrm{Ni}$ atoms in the $\mathrm{Mg}$-rich shell are pushed backwards as $\mathrm{Mg}$ has higher affinity for oxygen to form $\mathrm{MgO}\left(\Delta H=-601 \mathrm{~kJ} \mathrm{~mol}^{-1}\right)$ rather than $\mathrm{Ni}$ to form $\mathrm{NiO}$ $\left(\Delta H=-239 \mathrm{~kJ} \mathrm{~mol}^{-1}\right)$. Moreover, the surface energy of $\mathrm{MgO}$ is lower than $\mathrm{Ni}, \gamma_{\mathrm{MgO}}<\gamma_{\mathrm{Mg}}<\gamma_{\mathrm{Ni}}$, which also favors $\mathrm{MgO}$ to be an outer shell. Finally this leads to an outer $\mathrm{MgO}$ shell followed by a subsurface Ni shell. This process stops once $\mathrm{Mg}$ forms an $\mathrm{MgO}$ oxide of certain thickness because the electron transfer (tunneling) mechanism from the metal-oxide interface to the outer oxide surface, necessary for oxidation to occur, decreases exponentially at room temperature when the thickness of the oxide shell increases linearly., ${ }^{5,20,21}$ Remarkably, this process thus enables the formation of a multi-shell structure within a single NP.

Fig. 5(a) shows a bright field TEM image of the Mg-Ni NP produced with a higher discharge current of $0.400 \mathrm{~A}$, and Fig. 5(b) shows a corresponding HRTEM image demonstrating the presence of the intermetallic $\mathrm{MgNi}_{2}$ compound (in a mixed
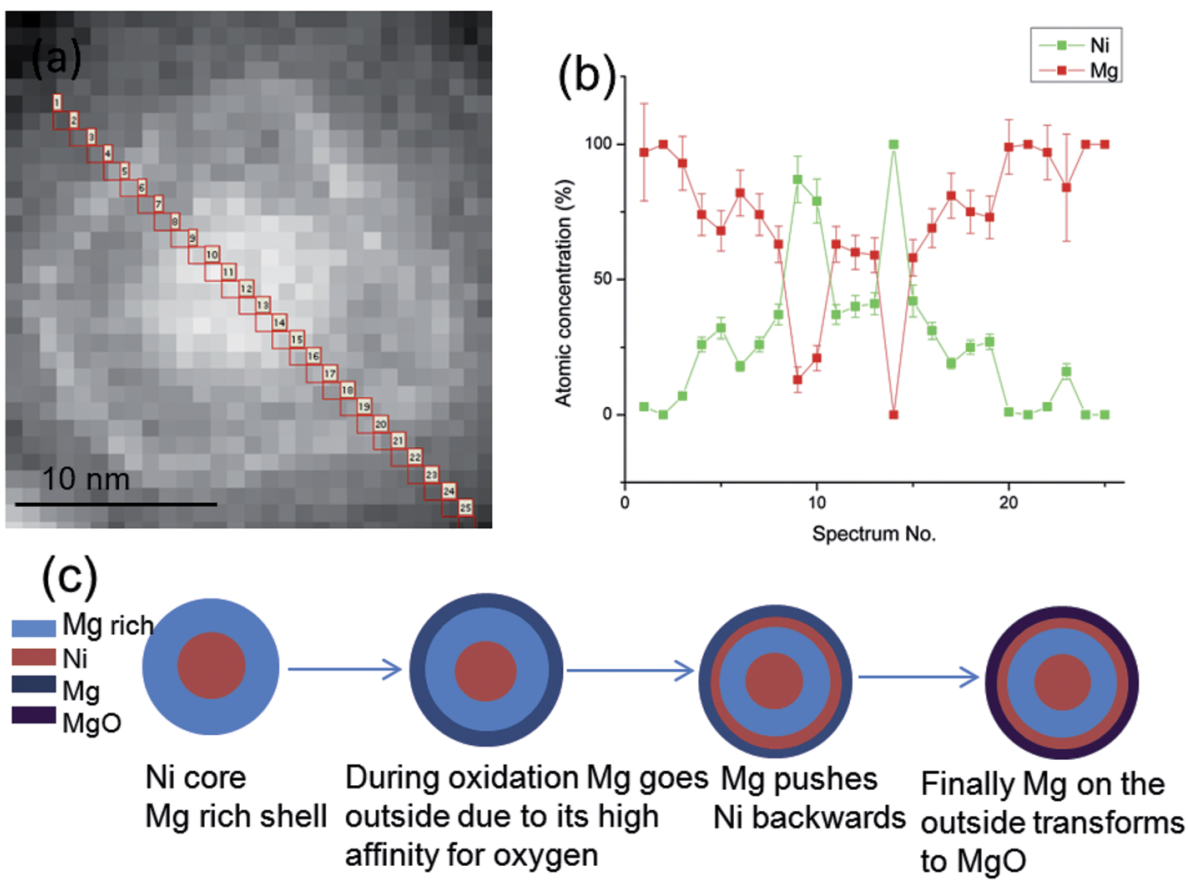

Fig. 4 (a) HAADF-STEM image of an Mg-Ni NP. (b) Composition line profile of the Mg-Ni NP from STEM-EELS, from spectra 1 to 25 as shown in (a) in red. (c) Schematic illustration of the multi-shell structure formation during oxidation of Mg-Ni NPs synthesized at $0.250 \mathrm{~A}$ discharge current. 


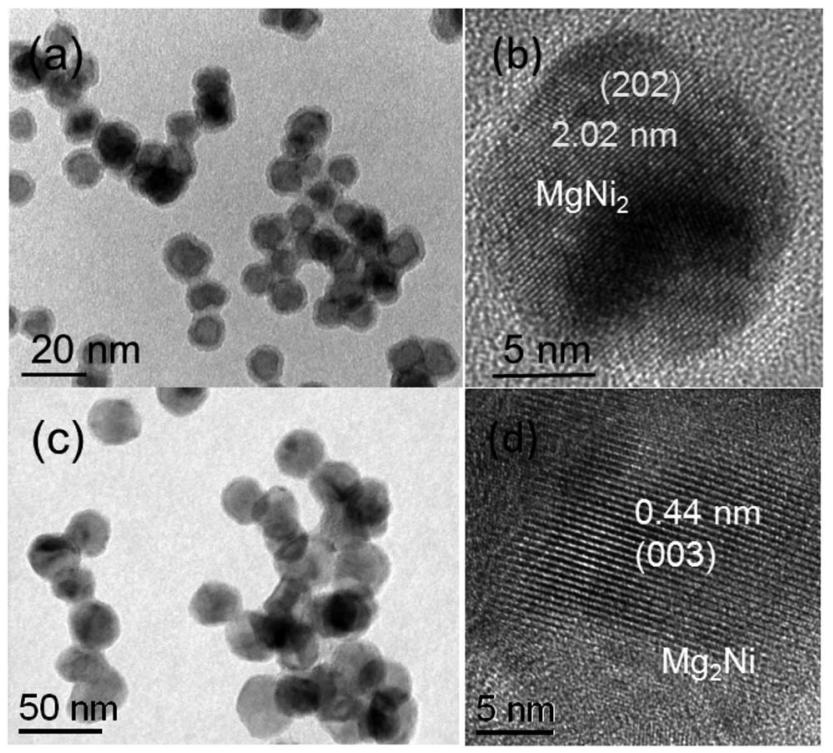

Fig. 5 (a) Bright-field TEM image of the Mg-Ni NPs produced at 0.400 $\mathrm{A}(1 / 2 \mathrm{Mg}+1 / 2 \mathrm{Ni}$ section targets). (b) HRTEM image of the intermetallic $\mathrm{MgNi}_{2}$ structure. (c) Bright-field TEM image of the $\mathrm{Mg}-\mathrm{Ni}$ NP produced at $0.350 \mathrm{~A}$ discharge current with $3 / 4 \mathrm{Mg}+1 / 4 \mathrm{Ni}$ section targets. (d) HRTEM image of the intermetallic $\mathrm{Mg}_{2} \mathrm{Ni}$.

state) with a clearly increased $\mathrm{Ni}$ at.\% than that produced in Fig. 3 ( $\sim 73$ versus $\sim 42$ at $\%$ Ni). Similarly, an intermediate current $0.350 \mathrm{~A}$ also shows a solid solution in the $\mathrm{Mg}-\mathrm{Ni}$ NPs but with a $\mathrm{Ni}$ concentration at an intermediate level ( $\sim 60$ at $\% \mathrm{Ni})$ between those obtained with 0.250 and 0.400 A discharge currents. The latter confirms the fact that at higher discharge current the temperature profile that these NPs undergo is in general higher allowing the formation of a solid solution/ intermetallic structure more enriched in the higher melting point element. However, for hydrogen storage applications we need Mg-rich particles as the increase in $\mathrm{Ni}$ concentration would not only increase the overall weight of the material but also simultaneously reduce the hydrogen storage capacity. Therefore, instead of using half section targets of $\mathrm{Mg}$ and $\mathrm{Ni}$, we adopted a section target of $3 / 4 \mathrm{Mg}$ and $1 / 4 \mathrm{Ni}$. As a result the $\mathrm{Mg}-\mathrm{Ni}$ NPs produced at $0.250 \mathrm{~A}$ show an increased $\mathrm{Mg}$ concentration of 80 at $\%$ in solid solution, which is in fact the result shown in Fig. 1(a)-(c). With a discharge current of $0.350 \mathrm{~A}$ an intermetallic $\mathrm{Mg}_{2} \mathrm{Ni}$ compound is formed consisting of $70 \mathrm{at} \% \mathrm{Mg}$ as shown in Fig. 5(c) and (d). The latter results again confirm the fact that at higher discharge current the (high vapor pressure) $\mathrm{Mg}$ concentration reduces against that of the high melting point element $\mathrm{Ni}$.

In order to see now the evolution of $\mathrm{Mg}-\mathrm{Cu}$ NPs with a similar strategy as for the $\mathrm{Mg}-\mathrm{Ni}$ system, we selected a section target of $1 / 2 \mathrm{Mg}$ and $1 / 2 \mathrm{Cu}$. Fig. 6(a) shows a HAADF-STEM image and Fig. 6(b) shows a bright field TEM image of the $\mathrm{Mg}$ $\mathrm{Cu}$ NPs produced at $0.250 \mathrm{~A}$. In comparison with $\mathrm{Mg}-\mathrm{Ni}$ under the same conditions, the Mg-Cu NPs also display a similar kind of structure. However, a detailed compositional line profile analysis of the NPs from STEM-EELS shows a variation of the $\mathrm{Cu}$ composition from the center to the outer surface of the NP as it is shown in Fig. 6(c) and (d). These profiles clearly show, unlike $\mathrm{Ni}$, that $\mathrm{Cu}$ does not have a pure core and a multiple shell structure but it rather forms a multiphase region from the center to the outer surface of the particles. The $\mathrm{Mg}-\mathrm{Cu} \mathrm{NP}$ structure consists of a core region, which is a solid solution rich in $\mathrm{Cu}$ as it is verified from HRTEM and HRSTEM images (see Fig. 6 in the ESI $†$ ). This is followed by an Mg rich solid solution region, a very thin $\mathrm{Cu}$ shell, and an $\mathrm{MgO}$ shell at the outer surface. Similar to the $\mathrm{Ni}$ case, $\mathrm{Cu}$ is also present at the subsurface as a shell before the $\mathrm{MgO}$ layer, as it can be seen in HAADF-STEM images of Fig. 6(a). Once the discharge current is increased further to 0.350 , it forms an $\mathrm{Mg}_{2} \mathrm{Cu}$ intermetallic. This is shown in Fig. 6(e) and the corresponding HRTEM image of Fig. 6(f), which displays the lattice spacing of the $\mathrm{Mg}_{2} \mathrm{Cu}(040)$ planes. Finally, as the discharge current is increased further to $0.400 \mathrm{~A}$, the NPs form a solid solution, Fig. $6(\mathrm{~g})$, with compared to $\mathrm{Mg}_{2} \mathrm{Cu}$ a further increase in $\mathrm{Cu}$ concentration.

If we compare now the $\mathrm{Ni}$ and $\mathrm{Cu}$ concentrations in $\mathrm{Mg}-\mathrm{Ni}$ and $\mathrm{Mg}-\mathrm{Cu}$ NPs produced under the same conditions, Fig. 6(h), it is evident that the Ni concentration is more than twice the one of $\mathrm{Cu}$. When the discharge current is increased the increase in concentration of $\mathrm{Ni}$ is also more pronounced than that of $\mathrm{Cu}$. This can be attributed to the differences in the rate of nuclei formation and their growth under that particular condition. To understand the formation of $\mathrm{Mg}-\mathrm{Ni}$ and $\mathrm{Mg}-\mathrm{Cu}$ NPs we have to understand the solidification of $\mathrm{Mg}-\mathrm{Ni}$ and $\mathrm{Mg}-\mathrm{Cu}$. From the $\mathrm{Mg}-\mathrm{Ni}$ equilibrium phase diagram, $\mathrm{Ni}$ will solidify first because it has a higher melting point of $1455^{\circ} \mathrm{C}$ as compared to that of $\mathrm{Mg}$ of $650^{\circ} \mathrm{C}$. In an atomic vapor of $\mathrm{Mg}-\mathrm{Ni}$, Ni will solidify first and form nuclei and then $\mathrm{Mg}$ will start to solidify on $\mathrm{Ni}$, because it is relatively easy for $\mathrm{Mg}$ to grow on Ni. This is also supported by our experimental observation that we do not see any separate pure Mg and Ni NPs. According to our previous observation on Mg NPs, Mg always tends to have a difficulty in homogenous nucleation, and it would require some species of impurity to nucleate. At 0.250 A discharge current (plasma temperature $\left(T_{\mathrm{p}}\right)$ $\left.=2.0 \times 10^{6} \mathrm{~K}\right), \mathrm{Mg}$ is able to grow relatively easy, as the thermal environment and gas temperature are relatively moderate and thus favorable for $\mathrm{Mg}$ growth. As the discharge current is increased further to $0.350 \mathrm{~A}\left(T_{\mathrm{p}}=2.6 \times 10^{6} \mathrm{~K}\right)$ or $0.400 \mathrm{~A}\left(T_{\mathrm{p}}=\right.$ $3.0 \times 10^{6} \mathrm{~K}$ ) (at constant gas flow), the temperature of the plasma is increased and the thermal environment the NPs experience is also changed favoring the formation of single alloy/solid solution NPs. Since Mg has relatively low solidification temperature it is not able to grow as easy in the $0.400 \mathrm{~A}$ plasma as it was in the $0.250 \mathrm{~A}$ one. These differences in nucleation and growth conditions for increasing discharge current thus favor a Ni-rich composition.

In the case of $\mathrm{Mg}-\mathrm{Cu}, \mathrm{Cu}$ solidifies and forms nuclei first and afterwards $\mathrm{Mg}$ grows on them, but the main difference with $\mathrm{Ni}$ is that $\mathrm{Cu}$ has (1) a clearly lower melting point than that of $\mathrm{Ni}$ $\left(1085{ }^{\circ} \mathrm{C}\right.$ versus $\left.1455{ }^{\circ} \mathrm{C}\right)$ and thus nucleates at temperatures more close to the solidification temperature of $\mathrm{Mg}\left(650^{\circ} \mathrm{C}\right)$ and (2) still better atomic mobility under these conditions than $\mathrm{Ni}$ and forms multi-phase structures instead of a multi-shell structure that is observed in $\mathrm{Mg}-\mathrm{Ni}$ NPs. Note that the phase diagram of both $\mathrm{Mg}-\mathrm{Cu}$ and $\mathrm{Mg}-\mathrm{Ni}$ is rather similar. Similar to 

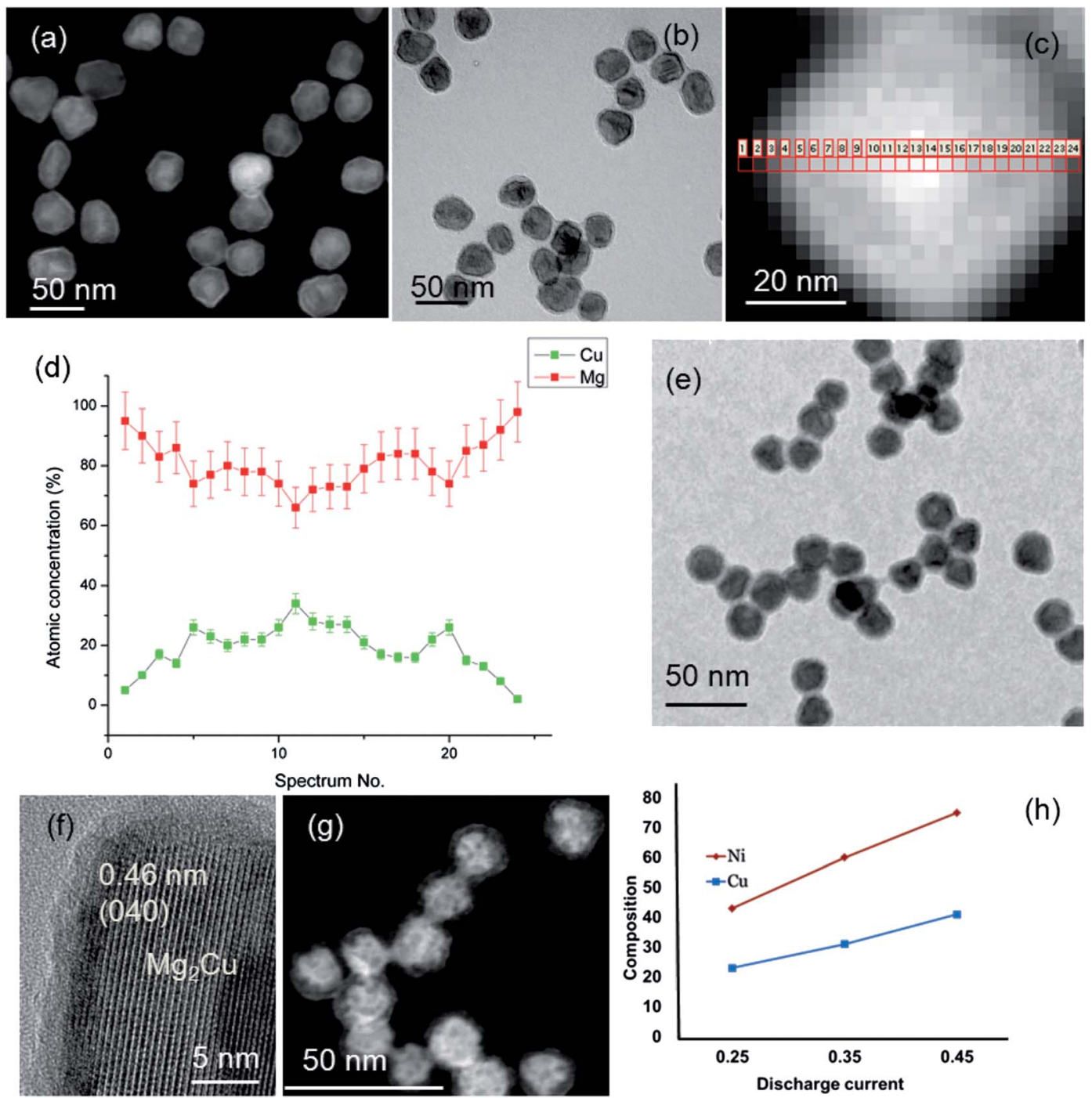

(h)

Fig. 6 (a) HAADF-STEM image of the Mg-Cu NPs synthesized at $0.250 \mathrm{~A}$. (b) Bright field TEM image of the same Mg-Cu NPs. (c) HAADF-STEM image of an NP synthesized at $0.250 \mathrm{~A}$ discharge current, whose composition line profile is shown in (d). (d) Composition line profile of the NP from spectra 1 to 24 as shown in (c). (e) Bright field TEM image of the $\mathrm{Mg}-\mathrm{Cu}$ NPs synthesized at $0.350 \mathrm{~A}$ with an intermetallic $\mathrm{Mg}_{2} \mathrm{Cu}$ structure. (f) HRTEM image of the intermetallic $\mathrm{Mg}_{2} \mathrm{Cu}$ structure. (g) HAADF-STEM image of Mg-Cu NPs synthesized at $0.400 \mathrm{~A}$ with a solid solution (alloy) structure, where the Cu composition is higher than that of the Mg-Cu NPs shown in (a) and (e). (h) Variation of Ni and Cu concentrations in the $\mathrm{Mg}-\mathrm{Ni}$ and $\mathrm{Mg}-\mathrm{Cu} \mathrm{NPs}$ produced at different discharge currents for $1 / 2 \mathrm{Mg}+1 / 2 \mathrm{Ni}$ section targets.

$\mathrm{Mg}-\mathrm{Ni}, \mathrm{Mg}-\mathrm{Cu}$ also forms single alloy/solid solution structured NPs at 0.350 and $0.400 \mathrm{~A}$ discharge currents, however the $\mathrm{Cu}$ concentrations in the NPs are observed clearly lower than the Ni ones (and the $\mathrm{Mg}$ concentrations thus higher, $c f$. Fig. 6(h)). This can be attributed to the lower melting point temperature difference between $\mathrm{Cu}$ and $\mathrm{Mg}$ than between $\mathrm{Ni}$ and $\mathrm{Mg}$. Similar behavior is also observed in the case of $\mathrm{Mo}-\mathrm{Cu}$, which has higher Mo concentration than $\mathrm{Cu}$ at a high discharge current of $0.550 \mathrm{~A}$ (Mo has a melting point of $2623{ }^{\circ} \mathrm{C}$ )..$^{10} \mathrm{In}$ addition, the NPs produced from a $3 / 4 \mathrm{Mg}-1 / 4 \mathrm{Cu}$ section target show a lower concentration of $\mathrm{Cu}$ as compared to that of $\mathrm{Ni}$, produced under exactly the same conditions, as it is shown in Fig. 5(c).

At higher discharge current, the cooling process is effectively reduced due to high temperature (kinetic energy) of the Ar gas molecules that act as a source for energy drain and nuclei formation. Since $\mathrm{Cu}$ has a high-energy transfer function and lower bond energy, its nucleation rate is diminished yielding a reduced $\mathrm{Cu}$ concentration within NPs. ${ }^{10}$ In the case of $\mathrm{Mg}$-Ti we also observe the concentration of $\mathrm{Ti}$ to increase at higher discharge current, i.e. similar behavior as observed for $\mathrm{Ni}$ and $\mathrm{Cu}$ in $\mathrm{Mg}-\mathrm{Ni}$ and $\mathrm{Mg}-\mathrm{Cu}$. However, we do not observe a multishell or multiphase structure as in $\mathrm{Mg}-\mathrm{Ni}$ and $\mathrm{Mg}-\mathrm{Cu}$, which reveals the important point that $\mathrm{Mg}$ is not able to dissolve in $\mathrm{Ti}$ at $0.250 \mathrm{~A}$ discharge current $(\mathrm{Mg}$ and $\mathrm{Ti}$ are immiscible) and pure $\mathrm{Mg}$ develops on top of a pure Ti core during NP formation. As a result no Ti subsurface shell is observed (see Fig. 7 in the ESI $†$ ). This also proves the oxidation mechanism of $\mathrm{Mg}-\mathrm{Ni}$ and $\mathrm{Mg}-\mathrm{Cu}$ produced at $0.250 \mathrm{~A}$ discharge current, where subsurface $\mathrm{Ni}$ and $\mathrm{Cu}$ are accumulated due to the displacement of $\mathrm{Ni}$ and $\mathrm{Cu}$ backwards within the NP. In $\mathrm{Mg}$ - $\mathrm{Ti}$ it is always pure $\mathrm{Mg}$ 
that surrounds $\mathrm{Ti}$ (no $\mathrm{Mg}$ rich area is present), which then logically implies that during oxidation subsurface Ti cannot develop.

\section{Conclusions}

We have demonstrated the synthesis of bimetallic Mg-based NPs (Mg-Ni, Mg-Cu, and $\mathrm{Mg}-\mathrm{Ti}$ ) with exceptional thermal stability during both their production and hydrogenation, where no void formation takes place. This exceptional thermal stability arises from (1) the addition of high melting point metals ( $\mathrm{Ni}, \mathrm{Cu}$, and $\mathrm{Ti}$ ) to $\mathrm{Mg}$ in a kind of solid solution and (2) the formation of hydride $\mathrm{MgH}_{2}$ before $\mathrm{Mg}$ evaporates. This stability is maintained for high $\mathrm{Mg}$ concentrations in the NPs up to 85 at\%. We also demonstrated a synthesis methodology for tuning the structure and composition of $\mathrm{Mg}$-based bimetallic NPs, which are of interest for high capacity hydrogen storage systems with enhanced surface to volume ratio architectures. Proof for the different NP structures synthesized has been provided by aberration-corrected TEM at the atomic and nanoscale level.

\section{Acknowledgements}

We would like to acknowledge the support for this work by The Netherlands Institute of Fundamentals Research for Materials (FOM). RFN and CG acknowledge the financial support of UEFISCDI through the PN-II-ID-PCE-2012-4-0362 project.

\section{References}

1 L. Schlapbach and A. Züttel, Nature, 2001, 414, 353.

2 R. W. P. Wagemans, J. H. van Lenthe, P. E. de Jongh, A. J. van Dillen and K. P. de Jong, J. Am. Chem. Soc., 2005, 127, 16675.

3 G. Krishnan, B. J. Kooi, G. Palasantzas, Y. Pivak and B. Dam, J. Appl. Phys., 2010, 107, 052504.

4 G. Krishnan, G. Palasantzas and B. J. Kooi, Appl. Phys. Lett., 2010, 97, 261912.
5 B. J. Kooi, G. Palasantzas and J. T. M. De Hosson, Appl. Phys. Lett., 2006, 89, 161914.

6 E. Callini, L. Pasquini, L. H. Rude, T. K. Nielsen, T. R. Jensen and E. Bonetti, J. Appl. Phys., 2010, 108, 073513.

7 A. Anastasopol, T. V. Pfeiffer, J. Middelkoop, U. Lafont, R. Canales-Perez, A. Schmidt-Ott, F. M. Mulder and S. W. H. Eijt, J. Am. Chem. Soc., 2013, 135, 7891.

8 J. P. Lei, H. Huang, X. L. Dong, J. P. Sun, B. Lu, M. K. Lei, Q. Wang, C. Dong and G. Z. Cao, Int. J. Hydrogen Energy, 2009, 34, 8127.

9 H. Shao, H. Xu, Y. Wang and X. Li, Nanotechnology, 2004, 15, 269.

10 G. Krishnan, M. A. Verheijen, G. H. ten Brink, G. Palasantzas and B. J. Kooi, Nanoscale, 2013, 5, 5375.

11 Y. Xu and J. Wang, Adv. Mater., 2008, 20, 994.

12 K. Watanabe, N. Ōkuma, Y. Fukai, Y. Sakamoto and Y. Hayashi, Scr. Mater., 1996, 34, 551.

13 H. Noh, J. D. Clewley, T. B. Flanagan and A. P. Craft, J. Alloys Compd., 1996, 240, 235.

14 B. Rodmacq, M. Maret, J. Laugier, L. Billard and A. Chamberod, Phys. Rev. B: Condens. Matter Mater. Phys., 1988, 38, 1105.

15 D. M. Borsa, R. Gremaud, A. Baldi, H. Schreuders, J. H. Rector, B. J. Kooi, P. Vermeulen, P. H. L. Notten, B. Dam and R. Griessen, Phys. Rev. B: Condens. Matter Mater. Phys., 2007, 75, 205408.

16 I. J. T. Jensen, S. Diplas and O. M. Løvvik, Appl. Phys. Lett., 2012, 100, 111902.

17 J. C. Fletcher, F. G. Arcella, G. G. Lessmann, R. A. Lindberg, Bimetallic junctions, U.S. pat. 4033504, 1977.

18 H. Lutz and O. Pous, Hydrogen Met., Proc. Int. Congr., 2nd, 1977, 2, $1 \mathrm{~F} 5$.

19 J. Qiu and J. Wang, Adv. Mater., 2007, 19, 1703.

20 A. T. Fromhold and E. L. Cook, Phys. Rev., 1967, 163, 650.

21 A. T. Fromhold and E. L. Cook, Phys. Rev., 1967, 158, 600. 